\title{
KRITIK TERHADAP KAJIAN HADIS FEMINIS ISLAM
}

\author{
RUSMIN ABDUL RAUF, UMMI FARHAH
}

UIN Alauddin Makassar, International Islamic University Malaysia

Email: rusmin.rauf@uin-alauddin.ac.id, farhahusman@gmail.com

\begin{abstract}
Abstrak
Artikel ini bertujuan untuk mengkritik kajian Feminis Islam utamanya berkaitan dengan Hadis. Ada empat poin yang utama yang dikritik dalam artikel ini. Pertama, penolakan terhadap hadis. Kedua, celaan terhadap sahabat. Ketiga, meragukan integritas Imam Bukhari. Keempat, reinterpretasi terhadap Hadis. Penulis menggunakan pendekatan ilmu musthalah hadis dalam menelaah dan menganalisa pandangan feminis islam. Penulis menemukan bahwa ada kecenderungan dari feminis untuk menolak hadis yang dianggap sebagai hadis misoginis terlepas apakah hadis tersebut shahih atau tidak. Sehingga dasar dari penilaian kesahihan hadis yang dipergunakan oleh feminis bukan lagi integritas dan ketersambungan sanad akan tetapi kesesuaian dengan nilai-nilai feminism atau tidak. Artikel ini menyimpulkan bahwa ada kecenderungan feminis islam tidak mengusai ilmu musthalah hadis dan cenderung menolak kaidah-kaidah ilmu yang telah ditetapkan oleh ulama demi menyesuaikan makna hadis dengan ide-ide feminism.
\end{abstract}

Kata Kunci

Hadis, misoginis, Feminis Islam

Abstract

This article aims to criticize the study of Islamic Feminism especially in relation to Hadith.

There are four main points criticized in this article. First, the rejection of hadith. Second, criticism of the companion. Third, doubting the integrity of Imam Bukhari. Fourth, the reinterpretation of Hadith. The author uses the musthalah hadith approach in studying and analyzing the views of Islamic feminists. The author finds that there is a tendency of feminists to reject a hadith that is considered a misogynistic hadith regardless of whether the hadith is authentic or not. So that the basis of the assessment of the authenticity of the hadith used by feminists is no longer the integrity and continuity of the chain of hadith but in accordance with the values of feminism or not. This article concludes that there is a tendency for Islamic feminists not to understand the science of hadith and tend to reject the principles of science that have been set by Islamic scholars to conform the meaning of hadith to the ideas of feminism.

\section{Keyword}

Hadith, misogynistic, Islamic Feminist 


\section{Pendahuluan}

Kajian tentang perempuan merupakan kajian yang menarik untuk terus didiskusikan. Banyak buku, artikel, essai berkaitan perempuan terus bermunculan. Kajian perempuan dan gender semakin semarak dan menarik perhatian. Kalangan feminis sering mendorong supaya kajian tentang perempuan terus dilakukan. Utamanya dengan menggunakan pisau analisis gender. Melalui perspektif gender ini, feminis melihat dan menilai segala persoalan. Mulai dari persoalan sosial, ekonomi, hukum, politik hingga masalah-masalah berkaitan fiqh dan tasawuf. Analisis gender telah menjadi neraca timbangan untuk menilai keadilan dan kepantasan segala sesuatu.

Al Quran dan hadis yang merupakan dasar dari Agama Islam pun tidak luput dari incaran feminis. Ayat-ayat dibedah, hadis-hadis dibongkar dengan menggunakan pisau gender. Segala ayat dan hadis yang tidak sesuai dengan ideologi dan agenda feminis kemudian dilabeli sebagai misoginis. Maka muncullah ayat- ayat misoginis, hadis-hadis misoginis, penafsiran misoginis, fikih misoginis. Seolah-olah Allah Swt. menciptakan makhluk bernama perempuan lalu Dia abaikan. Seakan-akan Nabi Muhammad Saw, mengangkat derajat wanita lalu kemudian merendahkannya. Seumpama ulama-ulama yang ikhlas adalah orang yang bias gender dan tidak menghormati perempuan.

Kajian hadis dengan analisis gender tentu menghasilkan hal yang berbeda dengan analisis ulama yang menggunakan pendekatan ilmu musthalah hadis. Karena bagaimanapun keduanya memiliki dasar yang berbeda. Ilmu musthalah hadis dilandasi pada keimanan kepada Allah Swt., dengan tujuan untuk lebih memahami apa makna dan maksud dari perkataan, perbuatan dan ketetapan Nabi Muhammad Saw. Sedangkan analisis gender didasarkan pada asumsi adanya ketidakadilan berbasis gender. Sehingga segala hal dicurigai sebagai bias gender. Tujuan yang dicapai adalah kesamaan antara laki-laki dan perempuan atau dengan istilah yang lebih halus kesetaraan gender.

Melalui analisis gender pun kemudian kita akan menemukan sebahagian feminis menolak hadis yang mereka anggap sebagai misoginis. Riffat Hassan mengatakan "These ahadith ought to be rejected on the basis of their content alone" (Hasan 1991). Hanya karena apa yang dia fahami dari hadis itu berbeda dengan keyakinannya. Ada kecenderungan dari Riffat Hasan menilai kebenaran hadis berdasarkan idealismenya sendiri. Sehingga hadis yang dia anggap bertentangan dengan ide feminisnya enggan dia terima.

Pada kasus yang lain, Fatima Marnessi ketika mendengar hadis "Tak akan baik keadaan sebuah kaum yang mengangkat wanita sebagai pemimpin urusan mereka." (Bukhari 1422 H) merasa bahwa ada yang salah dari isi hadis ini walaupun hadis tersebut diriwayatkan oleh Imam Bukhari. Maka kemudian Fatima Marnessi memeriksa hadis tersebut dengan menggunakan metode hermeneutika untuk mencari kelemahan hadis tersebut. Dia kemudian menemukan "kelemahan" pada sahabat Abu Bakrah ra. Menurut Fatima Marnessi, Abu Bakrah ra. ini membuat-buat hadis ini, karena ingin mengamankan posisi setelah kemenangan Ali ra. pada perang Jamal. Karena pada awalnya, Abu Bakrah ra. akan bergabung dengan Aisyah ra. namun 
kemudian tidak jadi. Maka karena khawatir Ali ra. yang merupakan khalifah akan mempersulit posisinya, maka Abu Bakrah ra. kemudian membuat Hadis ini. Penolakan Fatima Marnessi terhadap kredibilitas Abu Bakra ra. Karena Abu Bakra pernah dihukum had, menuduh orang berzina. Oleh karena itu, Fatima Marnessi kemudian berkesimpulan "If one follow the principles of malik for fiqh, Abu Bakra must be rejected as a source of hadith by every good, well informed Malikite Muslim”. (Marnessi 1991)

Adanya hadis-hadis seperti ini, yang dianggap tidak sesuai dengan agenda feminis di dalam kitab Bukhari menjadikan feminis ini kemudian meragukan kredibilitas Imam Bukhari dan Imam yang lain. Mereka berasumsi bahwa Imam Bukhari dan Imam yang lain yang memasukan hadis "misoginis" tidak cukup selektif dalam memilih hadis dan gagal dalam memahami semangat Al Quran dalam membela perempuan. Oleh karena itu, hadis-hadis dalam Shahih Bukhari diragukan kebenarannya oleh feminis tersebut. Bahkan mengajak untuk memeriksa kembali kesahihan hadishadis Bukhari utamanya dengan menggunakan perspektif gender. (Hasan 1991)

Selain itu, para pendukung gender juga mengajak untuk mengkaji ulang sejumlah hadis yang dinilai bias gender. Hadis-hadis yang seperti akan menimbulkan ketimpangan gender. Misalnya apa yang disampaikan oleh Nasaruddin Umar dalam pengantar buku "Perempuan di Lembaran Suci" karya Ahmad Fudhail. Beliau mengajak untuk kajian ulang terhadap hadis yang dinilai misoginis. Penafsiran ulang ini telah dilakukan oleh sebagian Feminis. Mereka menafsirkan hadis-hadis dengan perspektif gender. Memakai analisis gender untuk memahami hadis-hadis Nabi Muhammad Saw. (Umar 2005)

Dalam tulisan singkat ini, kami akan mengkaji pandangan feminis tersebut dengan menggunakan ilmu musthalah hadis.

\section{Menolak Hadis "Misoginis"}

Untuk lebih memahami tentang Hadis, kita akan memulai dari eksistensi Tuhan. Manusia ketika berpikir dengan benar, maka akan sampai kesimpulan bahwa manusia adalah makhluk yang diciptakan. Merenungkan tentang Alam, menghayati diri manusia itu sendiri, akan membawa kita kepada pencipta kita. Kebenarannya begitu simpel sehingga setiap manusia yang menggunakan akal pikirannya tanpa kecuali akan memiliki kesimpulan tersebut. Namun karena sederhana dan mudahnya menemukan kebenaran tersebut, banyak kemudian tidak puas dan merasa bahwa kebenaran itu terlalu mudah, sehingga meragukan kebenaran itu dan tetap berjalan mencari kebenaran hingga pada akhirnya tersesat dan tidak lagi menemukan jalan pulang.

Pencipta manusia dan alam semesta bernama Allah Swt. Para ulama telah merumuskan sifat wajib, mustahil, dan jaiz bagi Allah Swt. agar bisa mengenal Allah Swt. dengan benar dan tidak terjebak pada tuhan palsu. Allah Swt. menciptakan manusia dengan sebuah tugas, "Aku tidak menciptakan jin dan manusia melainkan agar mereka beribadah kepada-Ku” (QS. Adz Dzariyat: 56). Tugas manusia adalah beribadah kepada Allah Swt. Oleh karena itu, esensi manusia adalah hamba Allah Swt. Sebagai seorang hamba manusia wajib menaatiNya. Sebagai seorang hamba yang diciptakan, maka manusia adalah milik penciptanya. Tubuh manusia adalah milik TAHDIS Volume 11 Nomor 2 Tahun 2020 
penciptanya. Manusia hanya memiliki hak untuk mempergunakannya. Penggunaan ini, tidak boleh menyalahi perintah dari pemiliknya yaitu Allah Swt.

Kemudian Allah mengutus hamba pilihannya sebagai Nabi dan Rasul untuk mengajarkan kepada manusia bagaimana cara menyembah kepada Allah Swt. Karena akal yang dianugerahkan oleh Allah tidak mampu mengetahui cara menyembah dan beribadah kepada Allah sesuai yang dengan diinginkan oleh Allah Swt. Perkara ini memerlukan petunjuk dari wahyu yang disampaikan oleh Nabi dan Rasul. Di antara nabi dan rasul tersebut adalah Nabi Muhammad Saw. Nabi terakhir yang diutus untuk seluruh manusia sampai akhir zaman. Sebagai Nabi terakhir, maka bukti kenabiannya pun haruslah mampu membuktikan kenabian Nabi Muhammad Saw sampai akhir zaman. Bukti itu bernama mukjizat, dan mukjizat kenabian Nabi Muhammad Saw. Adalah Al Quran. "Dan jika kamu meragukan (Al-Qur'an) yang Kami turunkan kepada hamba Kami (Muhammad), maka buatlah satu surah semisal dengannya dan ajaklah penolong-penolongmu selain Allah, jika kamu orang-orang yang benar.” (Qs: AL Baqarah: 23)

Nabi Muhammad Saw sebagai seorang Rasul bertugas untuk menjelaskan wahyu yang diturunkan oleh Allah Swt. "Dan Kami tidak menurunkan Kitab (Al-Qur'an) ini kepadamu (Muhammad), melainkan agar engkau dapat menjelaskan kepada mereka apa yang mereka perselisihkan, serta menjadi petunjuk dan rahmat bagi orang-orang yang beriman." (QS. An Nahl: 64). Nabi Muhammad Saw, tidak hanya menjelaskan secara lisan, akan tetapi juga melalui praktik dalam kehidupan sehari-hari. Ini yang dinamakan Hadis. Maka hadis didefinisikan sebagai "Segala sesuatu yang disandarkan kepada Nabi Muhammad Saw. Baik berupa perkataan, perbuatan dan ketetapan (taqrir)" (Qasimy 1961). Oleh karena itu, hadis shahih sebagai penjelas dari Al Quran tidaklah mungkin bertentangan dengan Al Quran.

Keimanan kepada Allah mewajibkan manusia menaati perintah dan larangan Allah Swt yang disampaikan melalui Al Quran. Pada saat yang sama juga mewajibkan untuk menaati penjelasan dari Al Quran yang disampaikan oleh Nabi Muhammad Saw dalam bentuk hadis-hadis nabawi. Menaati keduanya adalah kewajiban bagi setiap muslim. Banyak ayat Al Quran yang menegaskan hal ini. Di antaranya "Apa yang diberikan Rasul kepadamu maka terimalah. Dan apa yang dilarangnya bagimu maka tinggalkanlah. Dan bertakwalah kepada Allah. Sungguh, Allah sangat keras hukuman-Nya”. (QS. Al Hasyr: 7), "Katakanlah (Muhammad), "Jika kamu mencintai Allah, ikutilah aku, niscaya Allah mencintaimu dan mengampuni dosa-dosamu." Allah Maha Pengampun, Maha Penyayang” (QS. Al Imran: 31). Maka tindakan menolak hadis adalah tindakan menolak perintah Allah Swt.

Sampai di sini, dapat disimpulkan bahwa menyifatkan kata misoginis kepada ayat $\mathrm{Al}$ Quran atau Hadis Nabi merupakan sesuatu yang tidak pantas dan merupakan sebuah celaan dan penghinaan kepada Allah Swt dan Nabi Muhammad Saw, karena Allah Swt menciptakan manusia dan memerintahkan mereka semuanya untuk beribadah kepadaNya. tanpa membedakan antara laki-laki dan perempuan. Begitu pula laki-laki dan perempuan memiliki hak yang sama untuk mendapatkan kebahagiaan di akhirat. Yang membedakan hanyalah ketakwaannya. Nabi 
Muhammad pun demikian, menghormati perempuan sebagaimana menghormati laki-laki. Sebagai seorang Rasul, Nabi Muhammad Saw. tentu mustahil melakukan perbuatan atau mengatakan perkataan yang merendahkan perempuan karena Rasul itu maksum. Kemaksuman adalah sifat yang tidak bisa dipisahkan dari kenabian. Oleh karena itu, menempatkan kata misoginis di belakang kata ayat/hadis adalah sebuah bentuk tuduhan bahwa Allah Swt dan Rasulullah Saw telah melakukan tindak diskriminasi terhadap perempuan. Tuduhan seperti ini adalah sesuatu yang tidak pantas dilakukan oleh orang yang masih ada iman di hatinya. Hanya orang yang diragukan keimanannya yang melakukan hal tersebut.

\section{Mencelah Sahabat}

Integritas seseorang dinilai bukan berdasarkan pengakuan dari orang itu sendiri, akan tetapi berdasarkan pengakuan dan persaksian dari orang lain yang mengenalnya dan telah terbukti integritasnya. Ulama hadis mengembangkan ilmu yang bernama al jarh wa at ta'dil. Ilmu yang membahas tentang integritas dan kredibilitas para perawi. Melalui ilmu ini kita akan mengenal yang mana perawi yang bisa diterima periwayatannya dan yang mana akan ditolak riwayatnya. Para perawi ini dinilai oleh orang yang sezaman dengan mereka atau yang datang setelahnya. Ada banyak kitab yang telah dikarang berkaitan dengan ilmu ini. Di dalamnya terekam penilaian tentang ke'adilan dan kedhabitan setiap perawi yang dinilai oleh ulama yang lain.

Sahabat-sahabat Nabi Muhammad Saw. tidak dinilai oleh orang yang datang setelahnya, karena keadilan para sahabat telah dinilai oleh Allah Swt dan Rasulullah Saw secara langsung. "Dan demikian pula Kami telah menjadikan kamu "umat pertengahan" agar kamu menjadi saksi atas (perbuatan) manusia dan agar Rasul (Muhammad) menjadi saksi atas (perbuatan) kamu." (QS. Al Baqarah: 143), "Kamu adalah umat terbaik yang dilahirkan untuk manusia,” (QS. Al Imran: 110). Rasulullah Saw bersabda: “Sebaik-baik era adalah zamanku” (HR. Bukhari Muslim). Berdasarkan persaksian dari Allah dan RasulNya ini, maka ulama membuat sebuah kaidah "Kullu sahabat 'udul", semua sahabat itu adil, dalam arti bahwa semua sahabat diterima periwayatannya, tanpa memeriksanya lagi. (Suyuti n.d.) Kalau Allah dan RasulNya telah memuji para sahabat, maka tidak diperlukan lagi pujian/celaan dari manusia., karena pujian/celaan itu sudah tidak ada lagi artinya. Sahabat didefinisikan sebagai orang yang bertemu dengan Nabi Muhammad saw., beriman kepadanya dan meninggal dalam keadaan Islam. (Salah 1986) Jadi, jin, orang kafir, munafik, murtad yang pernah bertemu dengan nabi tidak dikategorikan sebagai sahabat Nabi.

Adapun tuduhan Fatimah Marnessi yang mengatakan bahwa Abu Bakrah Ra membuat hadis karena ingin mengamankan posisinya, hanyalah asumsi dari Fatima Marnessi. Tidak ada bukti dan saksi yang bisa mendukungnya. Asumsi yang dibangun atas kecurigaan bahwa sahabat berani memalsukan hadis demi sebuah kedekatan dengan pemimpin waktu itu. Asumsi tanpa sanad seperti ini tidak perlu ditanggapi. Tanpa sanad setiap orang bisa membuat asumsi sesuai dengan kehendak hati masing-masing. Sedangkan kejadian Abu Bakrah dihukum had, karena menuduh orang berzina, hal ini berkaitan dengan persaksian. (Baladzury 1988) (Katsir 1988) Orang yang dihukum karena menuduh orang berzina ada dua keadaan. Pertama, menuduh karena TAHDIS Volume 11 Nomor 2 Tahun 2020 
ingin menjatuhkan seseorang, maka seperti ini menjadikan seseorang jatuh ke'adilannya. Kedua, orang menjadi saksi di pengadilan, namun tidak mencukupi sebagai bukti perzinaan yang mengharuskan empat saksi. Keadaan ini tidak menjatuhkan ke'adilan seseorang.

\section{Meragukan Integritas Imam Bukhari}

Islam memiliki keistimewaan yang tidak dimiliki oleh agama dan peradaban yang lain. Keistimewaan itu adalah Sanad. Hanya agama Islam yang memilikinya. Melalui Sanad ini, kemurnian Islam bisa tetap terjaga. Ibnu Mubarak berkata, "Seandainya bukan karena Sanad, maka semua orang akan berkata apa yang mereka inginkan” Ibnu Sirrin berkata, "Dulu mereka (Tabiin) tidak bertanya tentang Sanad Hadis sampai muncul Fitnah, untuk mengetahui yang mana ahli sunnah akan diterima hadisnya, dan yang ahli bid'ah akan ditolak hadisnya". (anNaesyabury n.d.) Sanad adalah jalan yang menyampaikan kepada matan atau isi hadisnya. Dengan kata lain, Sanad itu adalah rangkaian para perawi yang meriwayatkan dari gurunya yang terus berlanjut sampai ke Nabi Muhammad Saw.

Para perawi ini diseleksi berdasarkan sifat 'adilnya dan sifat dhabitnya. 'Adil ini berkaitan dengan integritas moral perawi yang menunjukkan ketakwaan dan kewibawaannya (muru'ah) sehingga timbul kepercayaan orang lain kepadanya, termasuk dalam hal ini meninggalkan dosadosa besar dan menjauhi dosa-dosa kecil. Secara otomatis orang yang fasik dianggap tidak memiliki sifat 'adalah sehingga pendapat dan riwayatnya tidak diterima. Sedangkan dhabit berkaitan dengan kecermatan dan ketelitian perawi. Tidak sembrono dan asal jadi. (Suyuti n.d., 61-62) Perawi juga harus terus terang dan tidak menyembunyikan sumber rujukannya baik sengaja maupun dengan tidak sengaja. Melalui persyaratan yang ketat ini, maka para perawi yang telah terbukti memiliki sifat 'adalah dan dhabit, merupakan para ulama yang memiliki integritas dan kredibilitas dalam periwayatan yang bisa diterima riwayatnya.

Hadis shahih tidak hanya mensyaratkan bahwa perawinya 'adil dan dhabit akan tetapi juga Sanad nya harus bersambung, tidak ada $d z a d z$ (bertentangan dengan dalil yang lebih kuat) dan illah (kecacatan) baik pada Sanad maupun pada matan. Maka ketika seorang perawi mengatakan sebuah hadis itu shahih, maka dia telah melakukan penelitian terhadap hadis tersebut dan hadis tersebut telah memenuhi syarat-syarat kesahihan hadis. Imam Bukhari menghafal dan mengumpulkan banyak sekali hadis. Kemudian menyeleksi dari hadis-hadis tersebut, dan hanya memilih yang shahih untuk dimasukkan ke dalam kitabnya. Tidak semua hadis shahih beliau masukkan karena takut bukunya menjadi sangat panjang. Kitab ini kemudian diberi nama " $A l$ Jami' Al Musnad Ash Shahih Al Mukhtasar min Umuri Rasulullah Saw wa sunanihi wa Ayyamihi”, biasa disingkat dengan Shahih Bukhari. Imam Bukhari tidak memasukkan satu hadis pun dalam kitabnya kecuali beliau salat dulu dua rakaat. Ini menunjukkan bagaimana Imam Bukhari tidak hanya memperhatikan aspek intelektual dalam menyusun bukunya, akan tetapi juga aspek spiritual sangat mewarnai proses penyusunan buku itu. 
Oleh karena itu, orang yang meragukan kemampuan Imam Bukhari dalam menyeleksi hadis bahkan memandang remeh Shahih Bukhari, maka orang itulah yang perlu diteliti dulu. Apakah dia memiliki kualitas untuk mengkritik Imam Bukhari atau tidak? Kalau tidak, maka kritikan itu tidak perlu dipedulikan. Karena bagaimana pun juga orang yang baru belajar suatu Ilmu, tentu berbeda pemahaman dengan orang yang telah lama mendalami ilmu tersebut. Seumpama orang yang baru bisa bikin pesawat dari kertas lalu mengatakan desain pesawat yang dibuat BJ Habibie ada kesalahan di dalamnya. Walaupun tidak bisa dipungkiri bahwa ada juga ulama yang memiliki kredibilitas dalam ilmu hadis mengkritik Shahih Bukhari. Misalnya Imam Daruquthni, menilai bahwa ada beberapa hadis di dalam Shahih Bukhari memiliki illat (cacat). Namun semua kritikan itu telah dijawab oleh Imam Ibnu Hajar dalam Muqaddimah Fath Bary. Hal yang perlu dicatat bahwa tidak ada seorang pun ulama baik laki-laki maupun perempuan yang mengkritik Shahih Bukhari sebagai kumpulan hadis yang merendahkan wanita. Orang yang mengkritik seperti itu hanyalah para feminis yang menggunakan kacamata analisis gender.

\section{Re-Interpretasi Hadis dengan Analisis gender}

Ada sementara anggapan bahwa Kajian Hadis terlalu fokus pada kajian Sanad, dan kurang memperhatikan matan. Bagi orang yang mempelajari Ilmu hadis dengan baik, tentu akan menolak pandangan ini. Kajian ilmu hadis tidak pernah melepaskan daripada kajian Sanad dan matan. Sejak dahulu keduanya senantiasa dikaji para ulama. Sanad dan matan, keduanya sangat penting dalam pandangan ulama. Ibnu al Madiny berkata: "Mengetahui perawi (Sanad) adalah separuh ilmu dan mengetahui fiqh hadis adalah separuhnya lagi". (ar-Ramahrumuzy 1404H) Imam Ahmad berkata: "Seandainya bukan karena Imam Syafie maka kami tidak mengetahui Fiqh Hadis". (Asyakir 1995) Ini adalah ungkapan dari ulama-ulama terdahulu yang menunjukkan pentingnya fiqh hadis. Fiqh hadis diartikan mengeluarkan makna, hikmah dan hukum-hukum dari hadis Nabi Saw. Pengertian ini menunjukkan bahwa yang mempelajari hadis itu datang ke Hadis dan mengeluarkan kandungan dari hadis itu. Bukan memutarbalikkan makna hadis agar sesuai dengan ideologi yang diyakini.

Oleh karena itu untuk mengetahui fiqh hadis, beberapa ilmu alat perlu dimiliki oleh pengkaji hadis. Setidaknya ada 5 ilmu yang perlu dikuasai:

1. Ilmu Bahasa Arab. Nabi Muhammad menyampaikan hadis dalam bahasa arab, maka wajib bagi setiap pengkaji hadis untuk mengetahui bahasa arab. Baik itu ilmu Nahwu, Sharaf, Balaghah, Sastra Arab, maupun arti kata-kata gharib (jarang yang digunakan).

2. Ilmu Musthalah hadis. Mengetahui dirayah dan riwayah hadis. Jarh wa ta'dil. Segala hal yang berkaitan ulumul hadis termasuk riwayat tentang penjelasan ulama terhadap hadis tersebut

3. Ilmu Ushul Fiqh. Mengetahui kaidah-kaidah dalam mengeluarkan hukum, memahami nash yang umum dan khusus, Nasikh wal Mansukh dan lain-lain yang berkaitan ilmu ushul fiqh 
4. Mengetahui maqashid Syariah. Mengetahui hikmah, dan rahasia-rahasia ketetapan Syariah. Mampu membedakan mana yang dharury, hajiyat, tahsiniyah.

5. Asbabul wurud. Keadaan dan kondisi munculnya hadis.

Kelima hal ini perlu dikuasai sebelum melangkah untuk menafsirkan hadis-hadis nabi Muhammad Saw. Tanpa hal tersebut, akan dikhawatirkan akan mengeluarkan hukum atau hikmah yang tidak sesuai dengan syariat Islam, sehingga justru jatuh kepada membenarkan yang batil dan menyalahkan yang hak.

Syekh Yusuf Al Qardhawi merumuskan cara memahami sunnah dengan benar. Setidaknya ada 8 hal yang harus diperhatikan:

1. Memahami sunnah sesuai dengan petunjuk al Quran

2. Menghimpun hadis-hadis yang memiliki tema yang sama

3. Menggabungkan atau mentarjih apabila ada hadis yang tampak bertentangan

4. Memperhatikan hadis dari sebab terjadinya dan tujuan hadis tersebut

5. Membedakan antara saran yang tetap dan sasaran yang tetap

6. Membedakan makna yang hakiki dan majazi

7. Membedakan hadis yang berkaitan dengan alam gaib dan nyata

8. Menegaskan konotasi dari lafaz Hadis

Ketika menjelaskan ini, Syekh Al Qardhawi mengingatkan agar tidak berlebih-lebihan dalam menggunakan kontekstualisasi dan menjelaskan makna majazi. Berlebihan dalam hal Itu dapat menjadikan makna hadis jauh dari makna sebenarnya. (al-Qardawy 1992)

Kemudian dari itu, perlu disadari bahwa ada hal-hal yang tsabit (tetap) dalam Islam dan ada yang mutagayyirat (berubah). Hal yang tsabit tidak boleh diubah karena hal tersebut telah menjadi ijma' ulama. Karena syariat Islam diturunkan untuk manusia. Kebudayaan dan peradaban boleh berubah, akan tetapi manusianya adalah manusia yang sama dengan yang di zaman Nabi, yang memiliki sifat untuk berbuat baik dan jahat. Oleh karena itu, penafsiran ulang tanpa memiliki ilmu yang memadai adalah dilarang. Begitu juga menafsirkan tidak sesuai dengan kaidah-kaidah agama yang tsabit juga dilarang.

\section{Kesimpulan}

Apa yang dituduhkan feminis berakar dari kurangnya dari mendalami ilmu hadis itu sendiri. Sehingga kemudian banyak melanggar kaidah dalam memahami hadis. Proses interpretasi hadis yang digunakan feminis dengan menggunakan analisis gender tidak sesuai dengan ajaran Islam karena analisis gender mendasarkan pemikirannya pada nilai materialisme yang bertentangan dengan nilai-nilai Islam. Maka pada hakikatnya, Islam tidak pantas dibedah dengan pisau analisis gender, akan tetapi feminismelah yang seharusnya ditimbang dengan menggunakan syariat Islam. Apakah sesuai dengan al Quran dan sunnah ataukah tidak. Karena Al Quran dan Hadis merupakan wahyu dari Allah Swt. Sehingga kebenarannya adalah kebenaran mutlak. Sedangkan teori feminisme adalah ide pemikiran manusia yang masih me imnulkan perdebatan. 
110 | Kritik terhadap Kajian Hadis Feminis Islam

Boleh jadi sekarang dianggap kebenaran, namun suatu saat nanti dianggap tidak lagi relevan. Sehingga tidak wajar jika yang selalu berubah dan tidak pasti digunakan untuk menilai yang sudah pasti dan tetap. Seharusnya, yang pasti itulah menilai yang tidak pasti. 


\section{DAFTAR PUSTAKA}

al-Qardawy, Yusuf. 1992. Dalam Kaefa Nata'amalu ma'a as-Sunnah an-Nabawiyah Ma'alim wa Dawabith, 93-181. Manshurah: Dar Wafa.

an-Naesyabury, Muslim bin al-Hajjaj. t.thn. "Muqaddimah Shahih Muslim." Dalam al-Musnad As-Shahih al-Mukhtashar binaqli al-adl'an al-adl ila rasulullah saw (Shahih Muslim), Juz 1, 14-15. Baerut: Dar Ihya Turats Al-Araby.

ar-Ramahrumuzy, Abu Muhammad al-Hasan bin Abdurrahman bin Khilad. 1404H. Dalam AlMuhaddis al-Fashil baena ar-Rawywa al-wa'i, 320. Baerut: Dar Fikr.

Asyakir, Abu al-Qasim Ali bin al-Hasan Ibn. 1995. Dalam Tarikh Damsyiq, Juz 51, 345. Baerut: Dar Fikr.

Baladzury, Ahmad bin Yahya bin jabir bin Daud al. 1988. Dalam Tarikh Buldan, 336. Baerut: Dar wa Maktabah al-Hilal.

Bukhari, Muhammad bin Ismail al. 1422 H. "al-Fitnah al-Laty Tamuju Kamauji al-Bahr." Dalam al-Jami' al-Musnad as-Shahih al-Mukhtashar min Umuri Rasulullah wa Ayyamih (Shahih Bukhari), juz 9, 55. Dar Thuqu an-Najah.

Hasan, Riffat. 1991. "The Issue of Women-Man Equality in the Islamic Tradition." Dalam Women's and Men's Liberation: Testimonies of spirit, oleh Riffat Hasan, Haim Gordon Leonard Grob, 80. Wesport: Greenwood Press, Inc.

Katsir, Abu Fida Ismail bin Umar bin. 1988. Dalam al Bidaya wa Nihaya, juz 7, 94. Dar Ihya Turats al-Araby.

Marnessi, Fatima. 1991. "A Tradition of Misogyny." Dalam The Veil and Male Elite $A$ Feminist Interpretation of Women's Right in Islam, 49-61. Perseus Book.

Qasimy, Muhammad Jamaluddin al. 1961. Dalam Qawaid Tahdis min Funun Musthalah Hadis, 61-64. Dar Ihya Kutub Arabiah.

Salah, Utsman bin Abdurrahman ibn. 1986. Dalam Ma'rifah Anwa' Ulum al-Hadis, 291. Baerut: Dar al-Fikr al Ma'ashir.

Suyuti, Jalaluddin As. t.thn. Dalam Tadrib Rawi, 674. Baerut: Maktabah Al KAutsar.

Umar, Nasaruddin. 2005. Dalam Perempun di lembaran Suci, oleh Ahmad Fudhail. Yogyakarta: Pilar Media. 